\title{
Terence Fisher and British Science Fiction Cinema
}

Science fiction has historically been one of the least discussed genres in British film culture. Until the publication in 1999 of a collection of essays edited by I.Q.Hunter ${ }^{1}$, serious consideration of Britain's contribution to the genre had frequently taken place in the margins of studies devoted mainly to the more obvious attractions of its American cousin. Few film scholars seemed willing to disagree with John Baxter's summation, made in 1970, that, with the exception of 2001: A Space Odyssey (1968), which in any case was directed by an American, 'the great British sf film has yet to be made.' (Baxter: 101). Hunter himself introduces his collection by conceding that 'the critical consensus remains, then, that British sf is a poor thing, responsive at periods to national discourses, but more often a shadow of its more ambitious, confident, expensive and expansive American counterpart.' (Hunter: 6). A similar view seems to have prevailed in relation to the science fiction films made at intervals throughout his career by Hammer's leading director, Terence Fisher. Despite Winston Wheeler Dixon's assertion that Four Sided Triangle (1952) 'far outdistances such conventional and overblown 1950s genre films as The Day the Earth Stood Still (1951) and Forbidden Planet (1956)' (Dixon: 4), Fisher's work in the genre has received scant attention, even from Dixon himself, and has been consistently overshadowed by Fisher's better known Gothic horrors such as his series of Dracula films.

This essay sets out to redress the balance by looking at the five science fiction films Fisher made during the 1950s and 1960s and at the significant part they played in the creation and development of an indigenous science fiction tradition within British film culture. For the sake of clarity, sf is defined here strictly in reference to films which Fisher made which have contemporary settings. This clearly differentiates 
them from films such as Curse of Frankenstein (1957) or The Two Faces of Dr Jekyll (1960) which might qualify as period sf, but are taken here to belong principally to the

Gothic strain in Fisher's work, or what might be described as a hybrid combination of sf and Gothic horror. These films have been extensively addressed elsewhere. The first two films, Four Sided Triangle and Spaceways (1953), made by Fisher for Hammer, were key to the establishing of the genre of contemporary sf in Britain in response to current developments in America. His later sf films, The Earth Dies Screaming (1964), Island of Terror (1966) and Night of the Big Heat (1967), which were all made by Fisher for small independent production companies, play out and extend themes and stylistic approaches which had come to the forefront of the genre during the real flowering of British sf films in the wake of The Quatermass Experiment (1955). In the final part of the essay, I will seek to draw parallels between elements of Fisher's work in the contemporary science fiction-thriller genre and the concerns which underlie his better-known achievements in Gothic horror or period sf.

\section{Fisher and the Beginnings of a New Wave in British Science Fiction}

The difficulties inherent in making a clear definition of what constitutes the science fiction genre have been well documented. J.P. Telotte has described it as a genre which 'tends to slip away, to evade its own evidence or facticity.' (Telotte: 3). Telotte opts for an approach which essentially uses the existing identified tradition of science fiction cinema, the body of work itself, as its own unifying definition. There is a reasonable assumption on his part that audiences will easily recognise the primary conventions of the genre, whilst being able to accommodate the changing nature of those conventions over time. For the purposes of this essay, it is useful to identify two key thematic strands within this tradition which are central to Fisher's particular 
contribution to the genre in Britain. Firstly, the expression of anxieties resulting from the possible consequences for humanity as a result of advances in technology made by scientists. This is clearly a perennial concern of the genre. Secondly, a wider concern based more loosely around the development of totalitarian or authoritarian political regimes, specifically in the aftermath of the World War Two. These two thematic trends clearly overlap in the postwar period, particularly in relation to the development of atomic weapons as part of the escalation of the Cold War. They are also, in their wider application, long-standing concerns within the canon of science fiction literature, from Edgar Allan Poe through H.G. Wells to Orwell's 1984.

What remains particularly appropriate in J.P. Telotte's approach is his recognition of the precise historical specificity of generic conventions. He acknowledges the central characteristic of these conventions in all genre film-making to be 'the fact that they are constantly changing in response to a variety of cultural and industrial influences.' (Telotte: 9) It follows that a full understanding of how those conventions work in relation to their audience is dependent upon placing them within both the wider socio-political context and within the traditions of the body of generic work of which they form a part. This is acutely relevant to science fiction when we consider the centrality of metaphor to the genre. As T. Shippey, writing about sf pulp magazines, neatly describes it: 'the fantastic elements of the stories were a cover, or a frame, for discussion of many real issues which were hardly open to serious consideration in any other popular medium: issues such as the nature of science.' (Shippey; 321). The metaphors constructed in Fisher's first two science fiction films reflect specific concerns emerging in Western culture in early postwar period.

These concerns had already begun to mark the emerging renaissance of science fiction cinema occurring in America in the early 1950s, which provides the 
model for Fisher's initial work in the genre. Telotte describes these films as playing upon 'our cultural fears of communist infiltration and of a cataclysmic world war.' (Telotte: 96). These anxieties are frequently embodied in the depiction of invasion by a superior, and seemingly unstoppable, alien force. Characteristic of this paranoia are films such as The Thing from Another World (1951), The War of the Worlds (1953) and It Came From Outer Space (1953), where valiant, ordinary Americans are forced to group together to repel the threat of annihilation from mysterious and malevolent forces bent on their destruction. The twin concerns with the dangers inherent in technological advances, particularly in wake of the use of atomic bombs at the close of World War Two, and the continuing threat of expanding totalitarian regimes are given explicit voice in The Day the Earth Stood Still (1951), where a highly advanced and civilised alien descends on the earth to deliver a warning to humanity about the possibly dire consequences of our continuing self-destructive tendencies. Here, technological development is seen as inherently dangerous when coupled with the self-evident inclination of human beings to use its potential for harmful purposes; a theme which was to dominate science fiction on both sides of the Atlantic for the coming two decades.

John Brosnan is probably correct in suggesting that British science fiction films in the 1950s closely followed their American counterparts in that 'during the first half of the decade they tended to reflect the underlying fears of the Cold War.' (Brosnan: 106). In Britain, these fears often focused on the danger of scientific secrets being given away to the Soviets. As Greta Jones has shown, the immediate postwar period in Britain was marked by increasing concerns over national security. This escalated following the arrest and prosecution of scientists such as Alan Nunn May and Klaus Fuchs for passing atomic secrets to the USSR and the defection in 1950 of 
the Italian-born physicist Bruno Pontecorvo, who had been working at the atomic laboratories at Harwell. (Jones: 42). These concerns are only too evident in Spaceways. The plot, written by Paul Tabori and Richard Landau from a radio play by Charles Eric Maine, concerns an American rocket scientist (played by Howard Duff) based in Britain who is accused of murdering his wife and her lover. We later discover that the wife's lover is, in fact, a spy intent on taking the secrets of rocket science with him as he heads 'east'. The threat from within is confirmed by the fact of his previous position of trust and authority at the research base where the film is largely set (a strikingly similar example of duplicity amongst scientists can be found in Anthony Asquith's The Net, released the same year). The ruthlessness of 'the enemy' is clear both from the way in which the spy deliberately casts suspicion on the innocent husband and by his final shooting of the wife when she refuses to flee with him. She makes the ideological values at stake quite clear in her final denunciation of her lover when she tells him she would rather remain a virtual prisoner on the base than go to a country where she would be just one amongst 200 million prisoners.

The anxieties at work in Four Sided Triangle also relate, if in a more generalised way, to the risks and possibilities of scientific and technological advance. Adapted by Fisher and Tabori from a novel by William F. Temple, the narrative centres on the attempts by two scientists to develop a form of cloning, whereby matter can be replicated. A clear distinction is drawn in the narrative structure between the two contrasting scientists. Robin (John van Eysen) is sensible and down-to-earth, seeking only to use the advances he is pioneering to help mankind towards a better life, whereas Bill (Stephen Murray) is driven by personal desire and emotional weakness; he tries to create a duplicate of the woman who has rejected him in favour of Robin. He meets with the inevitable punishment handed-out by the genre when his 
creation develops exactly the same preferences for Robin as its original. A fire in his laboratory sends both scientist and creation to their appropriate fiery moral end. Roslynn Haynes has described the, usually negative, stereotypes which have come to define popular images of the scientist. Bill fits neatly into her description of 'the alchemist ... driven to pursue an arcane intellectual goal that carries suggestions of ideological evil.' (Haynes: 3). The moral implications of Bill's obsession are made even more abundant by the film's closing quotation taken from Emerson: 'You shall have joy or you shall have power, said God, you shall not have both.'

In this sense, both films conform to the kinds of thematic concerns evident in their American models, a similarity confirmed by the casting of an American in the central role in Spaceways (although this was also a straightforward commercial ploy to try to attract American distributors). What makes the films more distinctive is the way that they reflect on some specifically British concerns, however obliquely. Kim Newman has argued that British sf films of the 1950s still seem to be 'fighting World War Two' (Newman: 79) and Peter Hutchings has suggested that they reflect a need, in the midst of cultural confusions brought about by increasing materialism and the influence of American popular culture, to restate more traditional national values and characteristics. (Hutchings: 34-41). This is most apparent in both Spaceways and Four Sided Triangle in the assumption of Britain's continued international standing as a major power. The importance of Britain's contribution to the developing atomic sciences is depicted as being at least equal in importance, if not superior, to the role of the United States. The depiction of scientists remains rooted in a pre-war, class-bound view of the 'boffin', as evidenced by Michael Medwin's almost unbearably decent Toby in Spaceways. There is a belief in the importance of self-sacrifice and consensus values up-held in the face of unseen enemies which clearly resonates with the ethos of 
'the people's war'. The same sense of stoic virtue and of the comfort provided by well-established social conventions permeates both films. As Steve Chibnall has pointed out, both films also reflect contemporary concerns about the changing status of women in postwar Britain (Chibnall: 58-60), whether this is manifested in Bill's doomed attempts to fashion a woman who will conform to his wishes in Spaceways or in the depiction of the independent and intelligent Dr Liza Frank (Eva Bartok) in Four Sided Triangle. What both films articulate is a deep-rooted anxiety in the face of accelerating change and a backward-looking nostalgia for a time when Britain's place in the world, and its assumed traditional values, could be taken for granted.

The achievement of these two films lies not so much in their intrinsic merits, which are certainly as limited as their budgets, but in their peculiarly British response to developments in the genre which were largely coming out of the United States. The tendency of earlier British sf had often been towards either prestigious literary adaptations, such as the Alexander Korda's production of Things to Come (1936), or towards the whimsical, with Ealing's characteristic The Man in the White Suit (1951). Fisher's films introduced a low-key realism and seriousness more in keeping with the ethos of the documentary-realist tradition or the Boulting Brothers' Seven Days to Noon (1950), perhaps the first British film to deal directly with the anxieties of the postwar atomic age. In their modest way, these films helped to establish the foundations of a distinctive approach to the genre in Britain which would come to fuller fruition over the next fifteen years.

'Do you really think there is something out there?' 'I know there is something out there.' 
This exchange of dialogue from The Earth Dies Screaming typifies the generalised sense of unease which is frequently the distinguishing feature of both British and American sf films from the mid-1950s to the mid-1960s. The parallel themes of Cold War paranoia and the fear of reduction at the hands of impersonal science produced a crop of American films of sustained critical interest and commercial popularity. The many variations on these themes played-out by the genre during this period included responses to the feared consequences of environmental poisoning from radiation, which found expression in the sequence of mutant-monster films typified by Them! (1954), with its depiction of giant ants marauding across an eerie desert landscape. The real possibilities of nuclear annihilation haunt films as varied as the sober On the Beach (1959) and The Bedford Incident (1965), to the more fantasy-based, allegorical Planet of the Apes (1968). Even the dehumanising effects on American society of Cold War paranoia itself (as evidenced by the witch-hunts carried out by Senator McCarthy and the HUAC) find their voice in Don Siegel's parable Invasion of the Body Snatchers (1956). The continuing potency of these metaphors is hardly surprising in a period that included the Cuban Missile Crisis, the continuing experimentation with chemical and nuclear weapons, and the increasing escalation of the Vietnam War. The intensification of social anxieties resulting from these events seems to have found its representation in the maturing and deepening of the sf genre in America.

In Britain similar anxieties can be traced. Greta Jones describes the rapidly escalating alarm at the prospect of a proliferation of nuclear weapons following the policy direction taken by successive governments in Britain from the late 1950s onwards. She charts the beginning of this intensification of public fears from the publishing of the Defence White Paper in 1957 which effectively committed Britain 
to the development of its own programme for creating an independent nuclear deterrent. (Jones: 111). One obvious manifestation of these concerns was the creation of the Campaign for Nuclear Disarmament (CND), which saw its peak of influence by 1960 when between one quarter and one third of the British public stated that they supported its aims; a fact reflected by a Labour Party conference resolution in favour of unilateral nuclear disarmament. (Marwick: 122). Another indication was the protest marches from the nuclear missile base at Aldermaston which began in 1958 and remained well supported until 1963. Britain's tendency to ally itself with America in the Cold War left it open to the same kinds of anxieties about attack from without and within, culminating a series of security scandals the most high profile of which was the probably the Profumo case. If the level of social unease had increased in America, then it seems to have found its counterpart in Britain.

The British science fiction films of this period with contemporary settings follow many of the traits associated with the American model. Fear of nuclear attack could take the form of an explicit commentary on the insanities of 'mutually assured destruction', as in the case of Stanley Kubrick's Dr Strangelove (1964), or metaphorical representations of Armageddon in the form of unprovoked alien attacks, as in Quatermass II (1957), Invasion (1966) and Quatermass and the Pit (1967). Quatermass II in particular played directly on public fears, in the wake of continuing sightings of UFOs, that the authorities were conspiring to keep what they knew about this phenomenon secret. The consequences of scientific, and especially nuclear, experimentation found its direct representation in The Day the Earth Caught Fire (1961), with its story of the earth being sent crashing out of its normal orbit as a result of the testing of nuclear weapons. It is also reflected in more allegorical terms with the mutation of poor Victor Caroon (Richard Wordsworth) into a form of living cacti 
in The Quatermass Experiment (1955), the latter being the film that really marked the maturing of the genre in Britain. ${ }^{2}$ In relation to the work of Fisher, the most significant of the British sf films of this period are probably those adapted from or inspired by novels by John Wyndham: Village of the Damned (1960), Children of the Damned (1963) and The Day of the Triffids (1963). In his reappraisal of these films, Andy Sawyer has suggested that Village of the Damned in particular encapsulates the anxieties unsettling the British public at that time, consisting of the Cold War, the threat of insidious invasion, totalitarianism and 'of a new generation which may not share the values of the old.' (Sawyer: 86). These films are also characterised by the low-key, sober, naturalistic approach which they adopt and which is reminiscent of the style Fisher had used in his earlier science fiction films. They also rely heavily in their creation of suspense and unease on the use of familiar settings and evocatively British visual motifs, which act to ground the bizarre events in a sense of the commonplace and everyday. It is exactly this combination of the fantastic and the mundane which marks out Fisher's science fiction films of the 1960s.

The creation of this feeling of unease in Fisher's films is firstly reliant upon the resonance of the symbols of national identity and culture he uses in the settings of all three films. Island of Terror takes place on an idyllic and isolated island off of the Irish mainland, but its visual geography is marked by such familiar British cultural icons as the tight-knit village community, complete with paternalistic local doctor and friendly policeman. Night of the Big Heat takes place against an equivalent Scottish island setting with most of its action centring on the local pub. This use of location and national cultural symbols harks back to the opening scenes of Four Sided Triangle where we are introduced to the setting though a series of iconic images of little England, from cricket pitch to pub and church, all of which is accompanied by a 
voice-over from the embodiment of civilised reason: the local doctor. The opening scenes of The Earth Dies Screaming achieve their impact precisely because the series of unexplained car, train, and aeroplane crashes, and the sudden physical collapse of ordinary citizens, takes place in such mundane and recognisable locations. This is typified by the bowler-hatted commuter mysteriously struck-down while awaiting his morning train to work. There is also a concentration on developing characters into more rounded individuals by elaborating on their relationships, particularly in the case of Night of the Big Heat, with its intertwined relationships consistently circulating around the meeting point of the village pub. This adds to the sense of familiarity, reminiscent, as it is, of British television soap operas. Fisher's directorial style, with his regular editing pace, static camera and flat lighting, add to the visual naturalism. Stylistically, the films conform to the tendency in all of Fisher's work to treat fantastical events in a coolly detached manner.

This underplaying of the fantastical elements in these films also serves to emphasise any allegorical meaning inherent in them. In The Earth Dies Screaming, Cold War tensions are again represented by the recurring motif of invasion. In this case the threat comes from an alien attack with poison gas which decimates the earth's population leaving only a handful of post-apocalypse survivors to give humanity hope. The dehumanising potential of Communism is clearly inferred by both the discovery that the anonymous, silver-suited aliens are actually robots and by the ability of these robots to transform any humans they touch into blind, zombie-like automatons. It is in this last aspect that the film most resembles the Wyndham sf films, mirroring the blindness inflicted on the earth's population in Day of the Triffids and the blank, emotionless children and brainwashed adults who populate Village of the Damned. The film also tellingly foreshadows the nightmarish landscape of George 
A. Romero's Night of the Living Dead (1968), with its images of deranged, mindless zombies plunging small town America into chaos.

Similarly, fear of invasion is also central to Night of the Big Heat, with another isolated community used as the site for the arrival of alien creatures searching for energy sources to feed on. However, the more convincing allegorical theme in the film relates the fear of scientific and technological development. The alien creatures travel by using various kinds of wave transmission, including radio and television, which allows them to potentially manifest themselves in the living rooms of every house in Britain. They also operate as a clear metaphor for nuclear contamination, with their glowing bodies emitting radiation, light and heat, and incinerating their human victims as a consequence. This impression is heightened in the atmospheric opening sequences of the film when the island is subject to a heat-wave in the middle of winter; a phenomenon which the locals attribute rather obliquely to 'the bomb'. Island of Terror even more explicitly reflects the fear of unrestrained science. Here, the creatures have been created as a direct result of the experiments of the arrogant $\mathrm{Dr}$ Philips at his laboratory, where his experiment supposedly designed to find a cure for cancer have actually produced a radioactive triffid-like monster who feeds on human bones. With an appropriate sense of ambiguity and irony, the creatures are finally disposed of through eating cattle infected with strontium 90.

These allegorical meanings are perfectly in keeping with the anxieties expressed in similar American films of the period, but, as with Fisher's earlier contemporary sf films, his work in the genre in the 1960s reflects some peculiarly specific British fears of the era. As I.Q. Hunter has suggested in relation to The Day the Earth Caught Fire, concerns about the development of youth culture and disaffected young people are a common thematic element in British sf of this period, 
from the alien children of Village of the Damned to the anarchy of A Clockwork Orange. (Hunter: 108-9). This is apparent in The Earth Dies Screaming, with the inclusion of the young couple Mel and Lorna. Mel, in particular, is a rebellious and surly young man, who makes a declamatory speech decrying the inequalities of his society. He is contrasted with the obviously upper class, establishment figure Taggart (Dennis Price), who is revealed to be self-serving and devious. However, any threat to established order that Mel might represent is mitigated by his development into a reliable hero and father of a newly born baby, who effectively represents the film's embodiment of future hopes.

A similar ambivalence is apparent in Island of Terror where the character of Dr David West (Edward Judd) is depicted as an archetypal 'swinging London' figure, but who eventually combines with the more traditionally heroic figure of Dr Stanley (Peter Cushing) to combat the imminent threat. In Night of the Big Heat, as Peter Hutchings has noted, the basis of the anxiety is as much centred on the disintegrating relationships precipitated by the arrival of a freewheeling 1960s free-spirit (Jane Merrow) as it is by the threat from marauding aliens. (Hutchings: 43). These anxieties are in contrast to the backward-looking certainties of Fisher's 1950s sf films. Whereas in the earlier films the return to a well-established social order could be relied upon, in his 1960s work the underlying sense of social cohesion has become frayed. This is confirmed by the ambiguous endings of the three films, with the survivors heading off to an uncertain future in The Earth Dies Screaming, the imminent outbreak of another attack by monsters in Island of Terror, and the final rescue in Night of the Big Heat being provided by providence, in the form of rain, rather than by any human intervention. This lack of final closure seems appropriate for the period of social and cultural upheaval in which the films appeared. 


\section{From Science Fiction to Gothic Horror: Visionaries and Rationalists}

If defining the boundaries of any film genre presents theoretical challenges, then science fiction provides a very specific area where those boundaries become particularly blurred; this is in its distinctive relationship to the horror genre. J.P. Telotte goes so far as to suggest that science fiction 'invariably' crosses-over into the realms of the horror genre and cites amongst his examples the case of the innumerable films based on the Frankenstein story. (Telotte: 5). He argues that Mary Shelly's Gothic original provides ample opportunities for the filmmaker to invest the story with contemporary resonances, referring to James Whale's 1931 adaptation as a film which 'couches its account of nineteenth-century grave robbing and stitched-together bodies in decidedly twentieth-century technological terms.' (Telotte: 180). This example is particularly appropriate when considering the work of Fisher as the mythology of the Frankenstein story remains central to so much of his work for Hammer in the Gothic horror genre, including five of the studio's Frankenstein films. Fisher's reworking of thematic aspects of the myth provides a direct link between his contemporary science fiction films and his more renowned work in the horror/period sf genre, as well as illuminating one of the characteristic concerns of his oeuvre.

Central to the Frankenstein story is, of course, the figure of the Baron himself, the very personification of what Roslynn Haynes describes as 'the Romantic depiction of the unfeeling scientist who has reneged on human relationships and suppressed all human affections in the cause of science.' (Haynes: 3 ). As she suggests, this remains the most enduring of all stereotyped images of the scientist and one whose connotations are almost exclusively negative, or at least tragic. The Frankenstein figure is invariably driven by a visionary zeal which leads him to cross the accepted 
boundaries of scientific enquiry and enter the territory of the morally forbidden, with the inevitable cataclysmic consequences for himself and humanity at large. As Telotte describes it, this figure may have its roots in nineteenth-century notions of the Romantic idealist, but it also highly applicable to science fiction's abiding concern with the damaging results of scientific and technological progress.

As well as having direct representation in Fisher's Frankenstein films, he reappears in a number of Fisher's science fiction films. In essence, Four Sided Triangle is a variation on exactly these themes. The film's visionary scientist, Bill, is marked out from the film's opening flashback sequences as a tormented figure who has suffered a painful childhood and whose abundant, but errant, talents have had to be supervised and contained by the paternalistic local doctor in order to keep them within reasonable bounds. His attempt to replicate his beloved Helen with a clone bears an obviously close relationship to the Frankenstein narrative, a fact reinforced by the laboratory sequences where Bill uses electricity as a rejuvenating force to give life to his creation. His actions lead to inevitable failure and his punishment, as he is burnt alive with his creature in his laboratory, re-enact a scene familiar from the finale of any number of adaptations of the Frankenstein story. In addition, Four Sided Triangle provides Fisher with the opportunity to work through ideas which reappear even more explicitly in Frankenstein Created Woman (1966), where the thematic concerns of the Frankenstein myth are complicated by the introduction of specific questions of gender identity. In both films, women are at once the object of obsessive male desire and subject to the attempts of a domineering male to refashion them for his own purposes. In Island of Terror, although the figure of Dr Philips, whose experiments have unleashed the homicidal creatures terrorising the local community, remains a cipher and is barely seen, his position within the narrative also mirrors the 
thematic concerns of the Frankenstein myth. This is reinforced by the visual appearance of his house, which has all the architectural stylistics of a classic Hammer Gothic set, complete with sinister laboratory hidden in the basement. The consequences of his infringements into morally forbidden territory remain the same: destruction.

As well as the figure of the Romantic visionary, Fisher's contemporary science fiction films play on another classic stereotype of the scientist, which Roslynn Haynes describes as 'the heroic adventurer in the physical or the intellectual world.' (Haynes: 3). Her suggestion that this figure has a strong appeal to adolescent audiences, because of his dynamism and powers of transcendence, certainly makes him a highly appropriate figure to have re-emerged in a period in which youth culture was central. He is represented in Spaceways by both Steve, the eager American engineer, and by Lisa Frank, who matches Steve in her implicit belief in the positive benefits of scientific endeavour. Their decision, at the end of the film, to spend their last moments alive relaying vital information from their doomed spacecraft is indicative of the idealistic ideology of this representation of science. In The Earth Dies Screaming a similar role is taken by the American test pilot Jeff Nolan (Willard Parker), whilst in Island of Terror we are presented with two representations of the stereotype in the form of Peter Cushing's fatherly Dr Stanley and Edward Judd's more aggressive Dr West. In both films these figures act as logical investigators whose function is to unravel inexplicable events and provide rational, if fantastical, explanations and solutions. The most blatant personification of the stereotype comes in Night of the Big Heat through the character of Hanson (Christopher Lee), whose pursuit of the truth is undertaken in a ruthlessly single-minded and superhuman manner. All of these versions of the type bear a close affinity to the depiction of Van 
Helsing in Fisher's versions of the Dracula myth for Hammer (Fisher was responsible for three entries in the series). Fisher's Van Helsing, particularly as played by Cushing in Dracula (1958), is a rationalist, whose abiding faith is in the power of reason to overcome the forces of disruption and moral chaos. The casting of Cushing in Night of the Big Heat and Island of Terror reinforces the thematic connections between Fisher's vision of this figure in both his science fiction films and his horror films.

The recurring appearance of these two figures, the dangerous visionary and the calculating rationalist, serve to play out Fisher's apparent fascination with the opposition between order and disorder. Within the context of his Gothic horror films, this is often used to foreground the clash between the rational and the irrational, but in his contemporary science fiction films it acts to express one of the most characteristic themes of the genre: the tension between the positive and negative aspects of technological and scientific progress. This tension, and its contradictory nature, is evidenced by the fact that in Fisher's science fiction films the potentially lethal consequences of scientific enquiry are usually averted by the application of an equally scientific solution (as in the conclusions of both Island of Terror and The Earth Dies Screaming). The elaboration of these themes, along with the metaphorical expression of Cold War anxieties, makes Fisher's science fiction films an essential part of the development of the genre in Britain. Their more culturally specific representations of the desire for order and the anxieties produced by social change, particularly within the rapidly altering context of Britain in the 1950s and 1960s, confirms their contribution to the creation of a distinctively national version of a genre which has more often been dominated by its American incarnation. 


\section{Bibliography}

Baxter, John, Science Fiction in the Cinema (London: Tantivy Press, 1970)

Brosnan, John, The Cinema of Science Fiction (London: Macdonald and Jane's, 1978)

Chibnall, Steve, 'Alien Women: The Politics of Sexual Difference in British sf Pulp

Cinema' in I.Q. Hunter (ed), British Science Fiction Cinema (London and New York:

Routledge, 1999)

Dixon, W.W. The Charm of Evil: the Life and Films of Terence Fisher (Metuchen and London: The Scarecrow Press, 1991)

Haynes, Roslyn D. From Faust to Strangelove: Representations of the Scientist in Western Literature (New York: Johns Hopkins University Press, 1994)

Hunter, I.Q. (ed), British Science Fiction Cinema (London and New York: Routledge, 1999)

I.Q. Hunter, 'The Day the Earth Caught Fire' in I.Q. Hunter (ed), British Science Fiction Cinema (London and New York: Routledge, 1999)

Hutchings, Peter, "We're the Martians now": British sf Invasion Fantasies of the 1950s and 1960s' in I.Q. Hunter (ed), British Science Fiction Cinema (London and New York: Routledge, 1999)

Jones, Greta, Science, Politics and the Cold War (London and New York: Routledge, 1988)

Marwick, Arthur, British Society Since 1945 (London: Penguin, 1996)

Newman, Kim, 'Are you now or have you ever been...?' in Stefan Jaworzyn (ed), Shock (London: Titan, 1996)

Sawyer, Andy, "'A stiff upper lip and a trembling lower one": John Wyndham on Screen' in I.Q. Hunter (ed), British Science Fiction Cinema (London and New York: Routledge, 1999)

Shippey, T. 'The Cold War in Science Fiction, 1940-1960' in Patrick Parrinder (ed), Science Fiction: A Critical Guide (London: Longman, 1979)

Telotte, J.P. Science Fiction Film (New York: Cambridge University Press, 2001)

\section{Notes}

${ }^{1}$ I.Q.Hunter (ed), British Science Fiction Cinema (London: Routledge, 1999) is part of Routledge's on-going series addressing various genres within British cinema.

${ }^{2}$ This revival owed a good deal to the influence of television: The Quatermass Experiment, as with all three of the Quatermass films, was adapted from BBC television serials scripted by Nigel Kneale. 